\title{
DROVE: An Algorithm for Spatial and Temporal Disaggregation of On-road Vehicle Emission Inventories
}

\author{
Carlos M. González*, Carlos D. Gómez, Beatriz H. Aristizábal* \\ Hydraulic Engineering and Environmental Research Group, Universidad Nacional de Colombia Sede Manizales, Cra 27 \\ 64-60 Bloque H Palogrande, Manizales, Colombia
}

\begin{abstract}
A key component of air quality management in urban areas is the analysis of pollutant emission distribution and hotspots, which are valuable information for developing emission reduction strategies and as input in air quality models. For vehicular emissions, this task is difficult because the sources are in constant movement and the availability of accurate and realistic vehicular activity information is scarce; a common issue in cities of emerging countries. Hence, exercises for estimating atmospheric pollutant emissions are developed only in a macro-scale way, without allocating in space and time the emissions. In this study, we present a new computational algorithm named DROVE, for the disaggregation of on-road vehicle emissions in space and time. DROVE is a free code developed in $\mathrm{R}$ and provides emission fluxes distribution from the estimation of disaggregation factors. It was designed with three possible approximations for spatial emissions disaggregation, considering the input information that would be available in the city: length of road segments (LRS), LRS + type of roads; and LRS + traffic flows. Two temporal distribution options are available for obtaining gridded hourly emissions. We evaluated the capabilities of DROVE for performing the $\mathrm{PM}_{10}$ emission distribution fluxes in the medium-sized cities of Manizales, Colombia, Antofagasta, Chile, and the megacity of Bogotá, Colombia. Results suggest that DROVE was able to allocate emission hotspots in zones of high traffic and main avenues (when information of the type of roads or traffic flow is available). Emissions distribution did not reflect this behavior when only LRS was used as input data, obtaining $50 \%$ of grid cells with percentage emission differences higher than $100 \%$ against the use of LRS + traffic flows. DROVE can be implemented in any region worldwide, could contribute with air quality management and provide disaggregated emission fluxes for air quality modeling.
\end{abstract}

Keywords: Emission inventories; Spatial-temporal disaggregation; On-road vehicular emissions.

\section{INTRODUCTION}

Urban areas in Latin American countries have been exposed during the last decades to a fast urbanization and economic growth, being the increases in traffic levels the most important contributor to air quality problems (Sun et al., 2016; Mangones et al., 2019). This is a key issue that affects human health and could be sever in cities of emerging countries (González et al., 2018). Latin American and the Caribbean are one of the most urbanized regions with $81 \%$ of its population living in urban areas in 2018 just, after Northern America with 82\% (United Nations, 2019).

\footnotetext{
* Corresponding authors.

Tel.: 5768879300 ext. 55337 ;

Fax: 5768879300 ext. 55129

E-mail address:

cmgonzalezd@unal.edu.co (C.M. González);

bharistizabalz@unal.edu.co (B.H. Aristizábal)
}

To tackle the air pollution derived from this urbanization process, it is necessary to improve air quality plans (AQP) by identifying and quantifying the sources that contribute the most to pollutant concentration levels, ensuring the application of regulatory actions and studying its dynamics and impacts (Thunis et al., 2019).

The analysis of emission fluxes from a high spatial resolution could provide information about air pollution hotspots in urban areas, which is a valuable information for developing emission reduction strategies. However, for vehicular emissions this task is difficult because the sources are in constant movement and it is necessary accurate information related with the emission activity such as, driving patterns, traffic flows and road network structure (Gómez et al., 2018).

The lack of detailed and accurate information about ground transport is a common issue in majority of Latin American countries, hence, there are difficulties not only for estimating precise macro-scale total emission fluxes at a national or regional level, but also for representing detailed spatial and temporal distribution of vehicular emissions 
(Romero et al., 2020). This fact establishes the need to count on reliable and flexible emission inventories (EI), that integrally describe the contribution of urban sources to atmospheric pollutants, following together a macro-scale approach and an accurate representation of disaggregated emissions at a local level. These improvements would contribute with air quality management, highlighting the benefits of accurate disaggregated emission fluxes for the application of air quality models (Borge et al., 2014; Alam et al., 2018; IbarraEspinosa et al., 2020).

When vehicular emission inventories are estimated from a complete bottom-up approach, it is possible to obtain the spatial distribution and temporal variability of emissions at a high spatial resolution. However, this process is complex and involves, for example, the use of traffic models for acquiring detailed traffic flow data. In majority of emerging countries vehicular emissions are scarce, and generally are obtained from top-down activity data accounting only for total emissions in the complete domain (de Sousa et al., 2019). Disaggregation of total emission fluxes could be performed from diverse disaggregation approaches, which include a group of methods with different levels of complexity; being a good option for cities in emerging countries, especially medium-sized cities (under 1 million inhabitants) (Tuia et al., 2007). These disaggregation approaches are based on the total amount of traffic emissions in the study area, going from a coarse geographic domain to a finer grid from specific data used to perform the distribution, e.g., population density maps, road network distribution, land use/cover maps or a combination of these (Loibl et al., 1993; Ossés de Eicker et al., 2008). A common characteristic of some disaggregation methodologies for spatial allocation of vehicular emissions (Tuia et al., 2007; Ossés de Eicker et al., 2008; Saide et al., 2009; Sahu et al., 2014; Gómez et al., 2018) is the combination of GIS tools and some of the information described above. The road network density is the base information used on these studies and is reported as suitable for vehicular emission disaggregation. However, the use of only this data has limitations such as a poor representation of differences in traffic activity and traffic behavior for distinct economic sectors, mainly in big cities. Improvements of emissions distribution were reported when additional information was included in the disaggregation process. For example, the use of road capacity, traffic count data or the simplification of the road network to only main roads. In general, these reference studies described the mathematical framework and the general steps for applying GIS procedures to disaggregate vehicular emissions; however, none reports a computational algorithm that could facilitate the application of a similar methodology for disaggregating vehicular emissions in any region worldwide.

In this paper, we present an algorithm for space and time disaggregation of on-road vehicle EI. The computational code named as DROVE (Disaggregation of on-ROad Vehicle Emissions), was developed on $\mathrm{R}$ language and allows performing the disaggregation of total vehicular emissions using three approaches of spatial distribution and two approaches of temporal distribution functions. Selection of the type of disaggregation approach depends on the availability of input information, which includes from basic data such as the distribution of road segments in the study area, to more complex information, such as traffic flow information. Furthermore, DROVE allows obtaining gridded emissions in a wide range of spatial resolutions (from hundreds of kilometers to a few meters). In order to show all different capabilities of DROVE, we performed the disaggregation of the on-road mobile emission inventory in the medium-sized Andean city of Manizales, Colombia. Furthermore, we present examples of DROVE application in other two Latin American regions, showing an exercise of spatial vehicular emissions disaggregation in the medium-sized city of Antofagasta, Chile, and the megacity of Bogotá, Colombia.

\section{METHODS}

We developed the algorithm for spatial and temporal disaggregation of on-road vehicle EI using $\mathrm{R}$ language. This computational code named hereafter as DROVE (Disaggregation of on-ROad Vehicle Emissions) was developed for contributing with the air quality management, not only with the analysis of emission hotspots in a specific region, but also for obtaining proper emission data to feed air quality models. We designed DROVE with two R scripts. The first one is the DROVE_UserInterface.R, where user can define the options for performing the emissions disaggregation. This process involves information such as the selection of the disaggregation approach, the specification of the number of vehicular categories that conform the total vehicular emission inventory and the definition if only spatial disaggregation or both spatial and temporal emissions distribution will be performed. The other script available with the code is the DROVE.R file, which contains the code algorithm and mathematical functions to perform the disaggregation process. User do not need to change data of this file.

DROVE is an open source code that can be download from https://sites.google.com/unal.edu.co/drove/home. The general framework of DROVE is shown in Fig. 1. The structure of the algorithm is composed by three main components: 1. Mandatory and optional input information, composed by data of total emissions, road network and grid cell distribution, which are included in the code through input tables. 2. Selection of disaggregation option and computational processing, which is based on the selection of one in three possibilities of spatial emissions disaggregation and two possible temporal functions for obtaining hourly emissions distribution. 3. Output data, where user could obtain disaggregation results in terms of total emissions per grid cell, as well as results of disaggregated emissions for each vehicular category.

\section{Input Data}

DROVE requires three types of input data tables (.csv or .txt files) which are mandatory for running the code. A table with total emissions from on-road vehicular sources in a specific region is required to perform the spatial and temporal disaggregation. In majority of cases, total emissions from on-road mobile sources are estimated using EI models (e.g., IVE, COPERT, MOVES) from a macro-scale approximation 


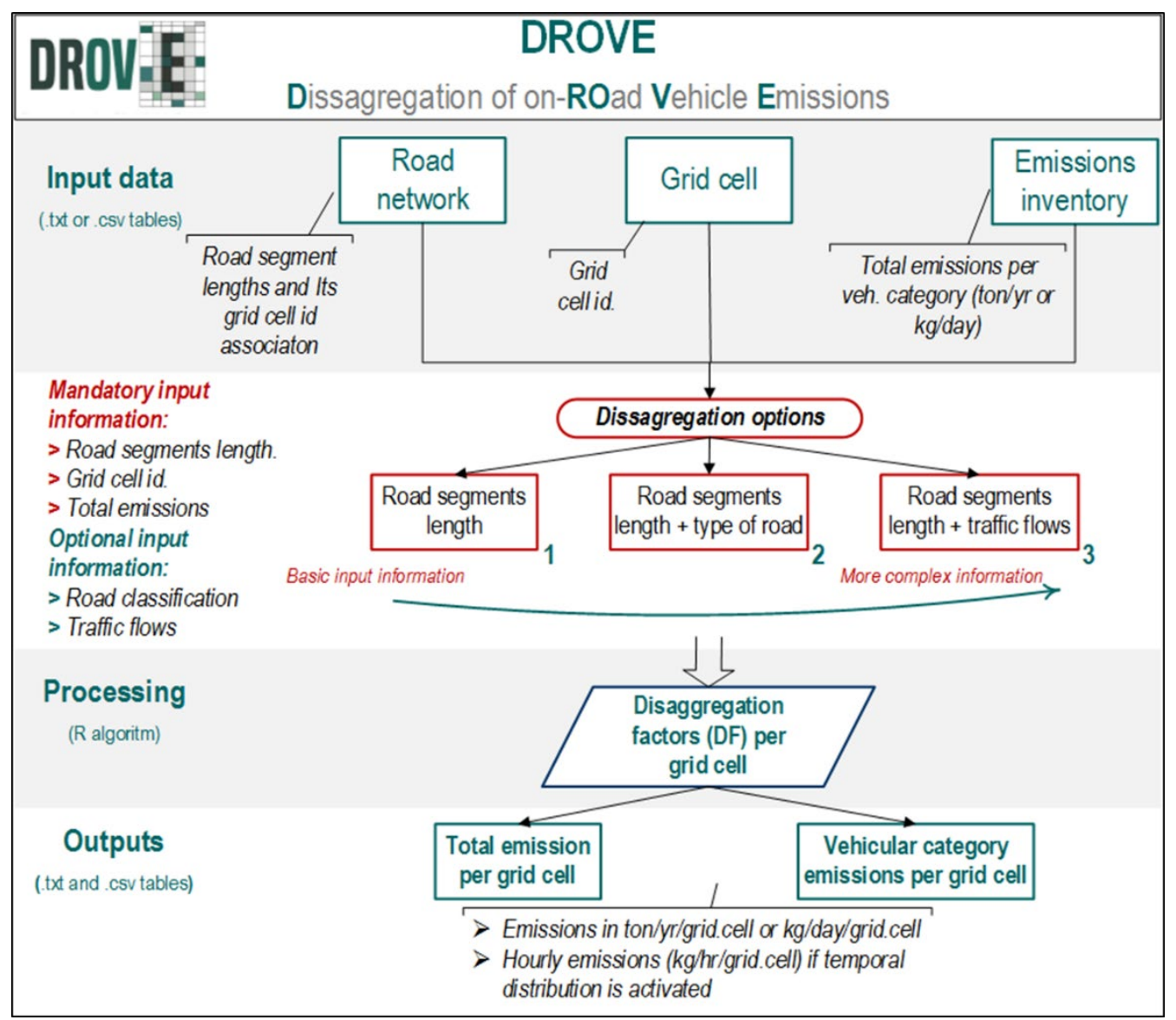

Fig. 1. DROVE general framework for the spatial and temporal disaggregation of on-road vehicle emissions.

for a country or city level, taking activity data from the local vehicle fleet registered and the average annual mileage. Generally, these emissions are not distributed in space and time. Hence, this input table should contain total emission fluxes of different pollutant species specified by user (ton $\mathrm{yr}^{-}$ ${ }^{1}$ or $\left.\mathrm{kg} \mathrm{day}^{-1}\right)$. Taking into account that majority of vehicular emission inventories are estimated in terms of different vehicular categories, user could specify in the input emission table the total emission for the complete vehicular fleet, or total emissions fluxes for different vehicular categories. This last option is useful because DROVE was designed for giving disaggregated emission results, not only in terms of total emission per grid cell for each pollutant, but also in terms of the emissions contribution of each vehicular category disaggregated in space and time.

On the other hand, it is necessary to define a domain and a grid cell distribution with a specific spatial resolution to perform the disaggregation. This information must be included in a table (.csv or .txt format) that contains a column with the number identification (FID) of each grid cell in the domain. Definition of EI domain and the grid cell map construction could be performed using a geographic information system (GIS) such as ArcGis or QGis. Spatial disaggregation in DROVE can be performed in a wide range of resolutions (from a coarse resolution of hundreds of kilometers to a high resolution of a few meters). Resolution of the grid-squared cells is selected depending on the objectives of the study. For example, a spatial resolution of $1 \mathrm{~km} \times 1 \mathrm{~km}$ is high enough to spatially find air pollution hotspots (Parra et al., 2006) and can be used for highresolution regional air quality modelling (Ossés de Eicker et al., 2008; González et al., 2018).

Finally, DROVE uses the information of the road network to perform the spatial disaggregation of emissions. The road network can be obtained from different sources such as the local government (e.g., transportation authority, the national bureau of statistics) or from open source information like OpenStreetMaps (https://www.openstreetmap.org). Mandatory information from the road network distribution should be organized in a table (.csv or .txt format) including the length of each road segment and the grid cell number association for each road segment, that is, the grid number where each road segment is located inside the cell domain. It is important to highlight that there is no a maximum or minimum length of the road segments for performing the disaggregation process. Users only must consider that, before the construction of the table with the road network information, the road network map and the grid cell distribution map must be intersected using, for example, a GIS program. Finally, the attribute table of the intersected shape must be exported. This intersection process allows to obtain a grid cell number association for each road segment, ensuring that there is not the same road segment inside more than one grid cell. With this information the algorithm computes the total length of 
road segments for each grid cell in the domain and divide this number by the sum of all road segments length, estimating disaggregation factors which are then multiplied by the total emission fluxes. The spatial disaggregation from only the road segments approach is denoted as option 1. Furthermore, optional additional information could be included in the road network table, for using the other two spatial disaggregation options available in DROVE. For example, option 2 needs information of the type of road for each segment (highway, arterial, residential); while option 3 requires traffic flow data, which could be obtained from a traffic model or from field vehicular counts. In the case of the information for using option 2, the type of road should be included in a new column of the road network table as a text variable with the following notation: "1_Hwy" for primary roads; "2_Art" for secondary roads; "3_ Res" for tertiary roads. On the other hand, for applying option 3 in DROVE, new columns in the road network table should be included (one for each vehicular category defined) with information of traffic flow, either in vehicles per hour or vehicles per day. Examples of the input data tables used in the present study were included in Section B of supplementary material. Complementary material can be obtained in both, the DROVE source code files and user's manual available in the download section of the DROVE web page (https://sites.google.com/unal.edu.co /drove/downloads?authuser $=0$ ).

\section{Disaggregation Options and Computational Processing Spatial Disaggregation Approaches}

DROVE algorithm was designed based on different spatial disaggregation approaches, which follow the equations reported by Saide et al. (2009) and adapted by Gómez et al. (2018). The spatial disaggregation process consists of calculating disaggregation factors (DFs) for each grid cell in the domain. The accuracy of the disaggregated emission inventory depends on the quality of the specific data used (e.g., road segments length, type of roads, traffic flow), which is the base for the estimation of disaggregation factors. DFs are then multiplied by total emission of each pollutant, giving emission fluxes per grid cell and ensuring mass conservation with respect to the total emission. The code allows the user to select one in three possibilities of spatial disaggregation.

The first disaggregation option (opt. 1) uses the length of road network segments per grid cell for estimating values of DFs according to the Eq. (1), where 1 is the total length of road segments contained in each grid cell $\mathrm{j}$ and $\mathrm{n}$ the total number of cells in the domain.

$$
D F_{j}=\frac{l_{j}}{\sum_{0}^{n} l_{j}}
$$

The second disaggregation option (opt. 2) uses information of the length of road network segments per grid cell and the type of road, for estimating DFs according to the Eq. (2). Here, DFs are calculated for each grid cell (j), each type of road $(k)$ and each vehicular category (i) using the same topdown approach from option 1 ; but including a weight factor (fm) for each vehicular category. This factor depends on the type of road and try to represent the differences in traffic flow. Three types of roads are included in the algorithm: highway (primary), arterial (secondary) and residential (tertiary) roads. User can define fm values from cero $(0)$ to one (1) for each type of road, taking care that sum of fm values for each vehicular category should be 1 in order to ensure mass conservation with respect to total emissions. Values of fm factor could be obtained from the analysis of traffic counts or traffic flow data. For using option 2 in a zone without information of traffic data, default fm values are included in DROVE, obtained from the analysis of traffic flow data reported by Steer Davies Gleave (2017) in the medium-sized city of Manizales, Colombia.

$$
D F_{j, i, k}=\left(\frac{l_{j}}{\sum_{0}^{n} l_{j}}\right) \times f m_{i, k}
$$

The third disaggregation option (opt. 3) uses information of the length of road network segments per grid cell and traffic flows. The estimation of DF is described in Eq. (3), where $\mathrm{F}$ is the traffic flow (vehicles $\mathrm{hr}^{-1}$ ) for each vehicular category (i). DFs are obtained from normalized weights for each cell in the EI domain from the information of traffic flow in a cell over the total traffic flow in a peak hour or a day for the study area.

$$
D F_{j, i}=\frac{l_{j} \times F_{j, i}}{\sum_{0}^{n} l_{j} \times F_{j, i}}
$$

\section{Temporal Disaggregation Approaches}

When temporal distribution is selected, DROVE performs the spatial and temporal disaggregation of emissions. Two options for hourly emission distribution are available. The first option denoted as automatic distribution, can be used when data related with a time distribution function is not available. This option allows building an automatic temporal distribution from a function that represents a typical traffic behavior in a city with short travel times. This automatic function was designed by joining three normal distributions with means at 7,12 and 18 hours considering as rush hours. The automatic distribution function conserves this profile and is independent of the city or region where DROVE is applied. On the other hand, the second option denoted as local distribution, allows including a unitary local temporal distribution function for applying to each vehicular category. DROVE includes in the code a default local distribution function for the city of Manizales, Colombia. This function was obtained from hourly traffic counts performed in the city during the last Mobility Plan study published by Steer Davies Gleave (2017).

\section{Output Data}

Outputs from DROVE comprise a set of tables (.csv and .txt files) with emission data per grid cell. When only spatial 
disaggregation is chosen, output data includes a table with total emissions (sum of all vehicular categories) per grid cell for each pollutant in ton $\mathrm{yr}^{-1}$ grid.cell ${ }^{-1}$ or $\mathrm{kg}_{\text {day }}{ }^{-1}$ grid.cell ${ }^{-1}$ (depending the unit used in emission input file). Furthermore, a table with total emissions per grid cell is built for each vehicular category. On the other hand, when temporal distribution is selected, a table with total hourly emissions per grid cell for each pollutant (in $\mathrm{kg} \mathrm{hr}^{-1}$ grid.cell ${ }^{-1}$ ) is reported; including also, tables with hourly emissions for each vehicular category.

\section{Description of Study Cases for Showing DROVE Capabilities}

In order to show examples of different results that could be obtained with DROVE, this paper shows its application for vehicular emissions disaggregation in three cities with distinct characteristics in terms of population and size. Input information for using DROVE in these cities was obtained from free official information and open web data.

The first case of DROVE application is the city of Manizales, Colombia. Manizales is a medium-sized city located on the western slopes of the central Cordillera of the Andes at $2150 \mathrm{~m}$ above sea level (Fig. 2). With a population of 400436 inhabitants in 2018 (DANE, 2020), and due to its location in a zone with a steep topography, the urban region is characterized by a limited area for growth; hence, the urban zone of the city is characterized by a relatively high population density $\left(\sim 7416\right.$ inhabitants $\left.\mathrm{km}^{-2}\right)$. Recently, the EI of the city was updated for the base year 2017 (CORPOCALDAS and UNAL, 2019). The EI reported total annual fluxes (ton $\left.\mathrm{yr}^{-1}\right)$ and daily fluxes $\left(\mathrm{kg} \mathrm{day}^{-1}\right)$ of criteria pollutants: carbon monoxide $(\mathrm{CO})$, nitrogen oxides $\left(\mathrm{NO}_{\mathrm{x}}\right)$, sulfur dioxide $\left(\mathrm{SO}_{2}\right)$, and particulate matter with diameter less than 10 and $2.5 \mathrm{~mm}\left(\mathrm{PM}_{10}, \mathrm{PM}_{2.5}\right)$; non-methane volatile organic compounds (NMVOC), black carbon (BC) and the greenhouse gases: carbon dioxide $\left(\mathrm{CO}_{2}\right)$, methane $\left(\mathrm{CH}_{4}\right)$ and nitrous oxide $\left(\mathrm{N}_{2} \mathrm{O}\right)$. The EI included the estimation of emissions from on-road mobile sources (exhaust, evaporative and resuspended particulate matter) and stationary sources (industrial-point and area). In the case of on-road mobile sources, five vehicular categories were included in the emissions estimation: passenger cars (PC), motorcycles $(2 \mathrm{w})$, taxis, public transport buses (Bus) and trucks. Results obtained suggested that emissions from vehicular sources dominated the EI in Manizales, with more than $90 \%$ of total emissions for most air pollutants estimated. For example, vehicular emissions of $\mathrm{PM}_{10}$ were estimated in 711 ton $\mathrm{yr}^{-1}$ ( $92 \%$ of total emissions), being buses and trucks the vehicular categories with higher contribution (56\% and $24 \%$ respectively) due to the use of diesel as fuel.

Table 1 shows emission fluxes $\left(\mathrm{kg} \mathrm{day}^{-1}\right)$ from different vehicular categories reported in the EI-2017 of Manizales, city, and used in this paper as input for spatial and temporal disaggregation with DROVE. The need for studding the impacts and trends of on-road mobile emission sources in Manizales is supported by the fast growth in the vehicle fleet of the city, with an increment around $28 \%$ of vehicles between 2014 and 2017 (being passenger cars and motorcycles the categories with higher growths, $27 \%$ and $32 \%$ respectively). Furthermore, comparing motorization rates of Colombian cities for the year 2018, Manizales reported one of the highest indexes with 455 vehicles per 1000 inhabitants, value higher than that reported in three principal cities of the country such as Bogotá (330 vehicles per 1000 inhabitants), Medellín (455 vehicles per 1000 inhabitants) and Cali (306 vehicles per 1000 inhabitants) (Manizales cómo vamos, 2019).

We performed the spatial and temporal disaggregation of vehicular emissions with DROVE in Manizales for two different resolutions: $1 \mathrm{~km} \times 1 \mathrm{~km}$ and $250 \mathrm{~m} \times 250 \mathrm{~m}$. The domain defined for emissions disaggregation and road network distribution of Manizales is shown in Fig. 2. Disaggregation exercise comprised the application of the three available

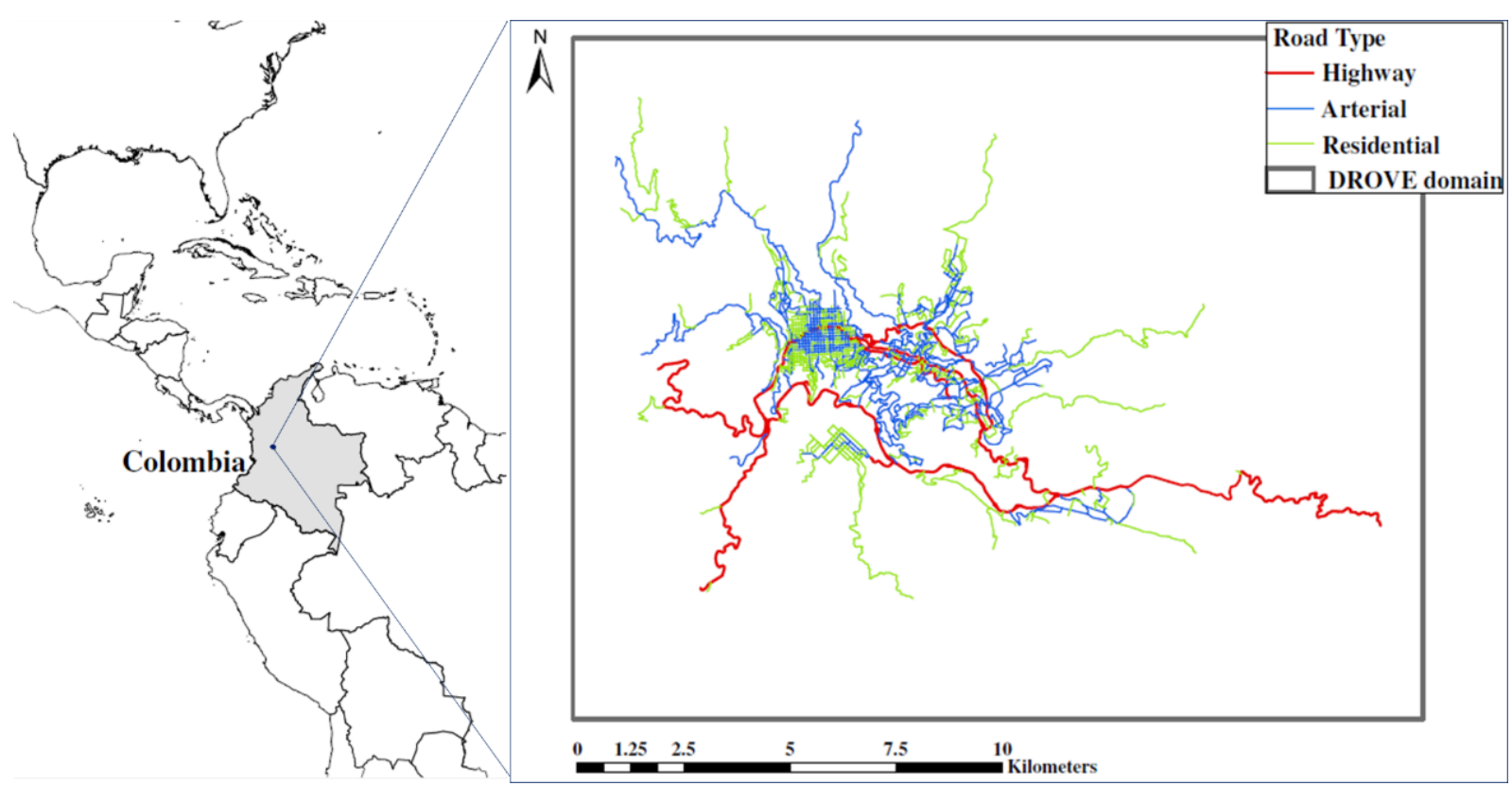

Fig. 2. Road network distribution in the city of Manizales, Colombia and DROVE domain for emissions disaggregation. 
Table 1. Summary of on-road vehicular emissions used in disaggregation exercises of the present study.

\begin{tabular}{|c|c|c|c|c|c|c|c|c|c|c|c|}
\hline Vehicular category & $\mathrm{CO}$ & NMVOC & $\begin{array}{l}\text { NMVOC_ } \\
\text { evap }^{\text {d }}\end{array}$ & $\mathrm{NO}_{\mathrm{x}}$ & $\mathrm{SO}_{2}$ & $\mathrm{PM}_{10}$ & $\mathrm{PM}_{2.5}$ & $\mathrm{BC}$ & $\mathrm{CO}_{2}$ & $\mathrm{~N}_{2} \mathrm{O}$ & $\mathrm{CH}_{4}$ \\
\hline \multicolumn{12}{|c|}{ Emissions reported in Manizales, Colombia, base year $2017\left(\mathrm{~kg} \mathrm{day}^{-1}\right)^{\mathrm{a}}$} \\
\hline Passenger car (PC) & 32282.0 & 2096.7 & 540.3 & 2525.7 & 59.6 & 190.8 & 107.5 & 53.9 & 668221.8 & 34.3 & 1612.2 \\
\hline Motorcycle $(2 \mathrm{w})$ & 35150.6 & 10139.9 & 1002.0 & 601.4 & 14.6 & 374.1 & 269.8 & 52.6 & 150117.9 & 0.4 & 2028.0 \\
\hline Taxi & 13939.2 & 198.1 & 295.1 & 729.4 & 7.0 & 33.6 & 18.8 & 7.8 & 178302.6 & 9.5 & 1386.7 \\
\hline Bus & 2478.5 & 578.1 & 0.0 & 7367.3 & 3.9 & 1085.4 & 976.4 & 684.0 & 390493.6 & 5.4 & 0.0 \\
\hline Truck & 1735.7 & 320.5 & 1.0 & 2922.6 & 1.7 & 469.6 & 422.0 & 305.1 & 164219.1 & 4.9 & 1.8 \\
\hline \multicolumn{12}{|c|}{ Emissions reported in Antofagasta, Chile, base year $2018\left(\text { ton } \mathrm{yr}^{-1}\right)^{\mathrm{b}}$} \\
\hline Passenger car (PC) & 1051.0 & 160.9 & & 233.0 & 2.2 & 22.9 & 16.2 & & 30.4 & 43.9 & 5.9 \\
\hline Motorcycle (2w) & 41.7 & 17.4 & & 1.5 & 0.0 & 0.4 & 0.3 & & 329.2 & 0.0 & 1.1 \\
\hline Taxi & 84.5 & 17.9 & & 56.4 & 0.2 & 21.6 & 19.1 & & 22816.5 & 2.0 & 2.5 \\
\hline Bus & 684.4 & 251.5 & & 224.7 & 1.0 & 120.1 & 115.9 & & 158240.4 & 4.6 & 25.9 \\
\hline Truck & 117.2 & 9.6 & & 64.2 & 0.2 & 3.7 & 3.0 & & 24899.1 & 2.6 & 0.7 \\
\hline \multicolumn{12}{|c|}{ Emissions reported in Bogotá, Colombia, base year $2014\left(\text { ton } \mathrm{yr}^{-1}\right)^{\mathrm{c}}$} \\
\hline Passenger car $(\mathrm{PC})^{\mathrm{e}}$ & 346173.5 & 35181.4 & & 23688.5 & 9244.6 & 158.2 & 131.3 & & 672 & & \\
\hline Motorcycle (2w) & 298968.0 & 52772.2 & & 5922.1 & 669.9 & 92.3 & 76.6 & & 1164730.4 & & \\
\hline Taxi & 39337.9 & 13193.0 & & 12831.3 & 1205.8 & 26.4 & 21.9 & & 1035315.9 & & \\
\hline Bus & 15735.2 & 0.0 & & 24675.5 & 937.9 & 303.1 & 251.6 & & 1811802.9 & & \\
\hline Truck $^{\mathrm{f}}$ & 86543.4 & 8795.4 & & 31584.6 & 1339.8 & 738.1 & 612.6 & & 2200046.3 & & \\
\hline
\end{tabular}

a Data obtained from CORPOCALDAS and UNAL (2019).

${ }^{\mathrm{b}}$ Data obtained from the web page of Chilean Environment Ministry (https://datosretc.mma.gob.cl/group/emisiones-al-aire).

${ }^{\mathrm{c}}$ Data obtained from SDA (2017).

${ }^{\mathrm{d}}$ Emission of NMVOC from vehicle evaporative processes.

e Include emissions for the sum of vehicles from the reported categories: automobile, camper, van.

${ }^{\mathrm{f}}$ Include emissions for the sum of trucks for cargo and special transport.

disaggregation options. In order to compare differences among results, option 3 (length of road segments + traffic flows) was assumed as the reference case for Manizales. This assumption is supported by the studies of Ibarra-Espinosa et al. (2020) and Alam et al. (2018), which suggest that traffic flow estimates are the most representative components for emission distribution following a bottom-up approach. Information of traffic flows in Manizales was obtained from the traffic model EMME, which was applied in the study of Manizales Mobility Plan (Steer Davies Gleave, 2017). EMME is a flexible and comprehensive transportation planning software used for travel demand simulations. This model can supply activity data information (i.e., traffic flows) from input data like the road network topologies, origin-destination matrices and different calibration parameters such as road network nodes, links and zones (Mangones et al., 2019). Hence, information of traffic flows obtained in Manizales could be consider as a good representation of a realistic behavior of traffic in the city.

On the other hand, the maps shown in results section are focused in disaggregation of $\mathrm{PM}_{10}$ emissions, one of the most important pollutants measured in the air quality monitoring network of the city. Output tables (.csv format) with results for all pollutants described in Table 1 are presented in supplementary material (section B).

In order to show the application of DROVE in other regions of the world, we chose two different cities for performing the spatial disaggregation of vehicular emissions: Antofagasta, Chile (Fig. S1), and Bogotá, Colombia (Fig. S2). Total vehicular emissions (ton $\mathrm{yr}^{-1}$ ) of the medium-sized city of Antofagasta (population: 361873 inhabitants in 2017 (INE, 2020)) were obtained from the EI year base 2018 (Table 1) reported from Chilean Environmental Ministry (https://mma.gob.cl/aire/). On the other hand, total vehicular emissions (ton $\mathrm{yr}^{-1}$ ) of the megacity of Bogotá (population: 7181469 inhabitants in 2018 (DANE, 2020)) were obtained from the EI year base 2014 (Table 1) reported by SDA (2017). Shapefiles with road network distribution of both cities were obtained from OpenStreetMaps (https://www.op enstreetmap.org). We implemented the spatial emission disaggregation for both cities using DROVE options 1 (road segment length) and 2 (road segment length + road type), in order to show differences from these approaches. In the case of option 2, road type was assigned from the analysis of the fclass attribute in downloaded shapefiles (see attribute association in Table $\mathrm{S} 1$ of supplementary material). Input tables with road network and grid cell distribution of Antofagasta and Bogotá are included in supplementary material (section B).

\section{RESULTS AND DISCUSSION}

\section{Spatial Disaggregation of On-road Vehicular PM10 Emission in Manizales Using the Three Disaggregation Options}

The spatial disaggregation of $\mathrm{PM}_{10}$ vehicular emissions performed with DROVE in Manizales, suggests that $\mathrm{PM}_{10}$ emission hotspots are associated with the principal avenues of the city (highway roads), where main hotspots were concentrated at downtown area (geographic center) and south 
region - zone characterized by the presence of the municipalbus terminal. This result is shown in Fig. 3(a) and was obtained from the use of option 3 (base case) disaggregation in DROVE, which uses traffic flows information and length of road segments as disaggregation parameters. This behavior was observed not only with the highest grid cell resolution evaluated $(250 \mathrm{~m} \times 250 \mathrm{~m}$, Fig. 3(a) right), but also for the coarse resolution $(1 \mathrm{~km} \times 1 \mathrm{~km}$, Fig. 3(a) left), suggesting the capability of DROVE for representing differences in emission zones in medium-sized cities such as Manizales, characterized by a small urban area $\left(\sim 54 \mathrm{~km}^{2}\right)$.

We present also in Fig. 3 , the spatial disaggregation of $\mathrm{PM}_{10}$ emissions obtained with the other two spatial disaggregation options available in DROVE. Emission maps obtained with option 1 distribution (road segments length) show the highest emission hotspot around downtown Manizales and its nearby regions (Fig. 3(c)), in a zone characterized by the highest density of road network but with the presence of (a)

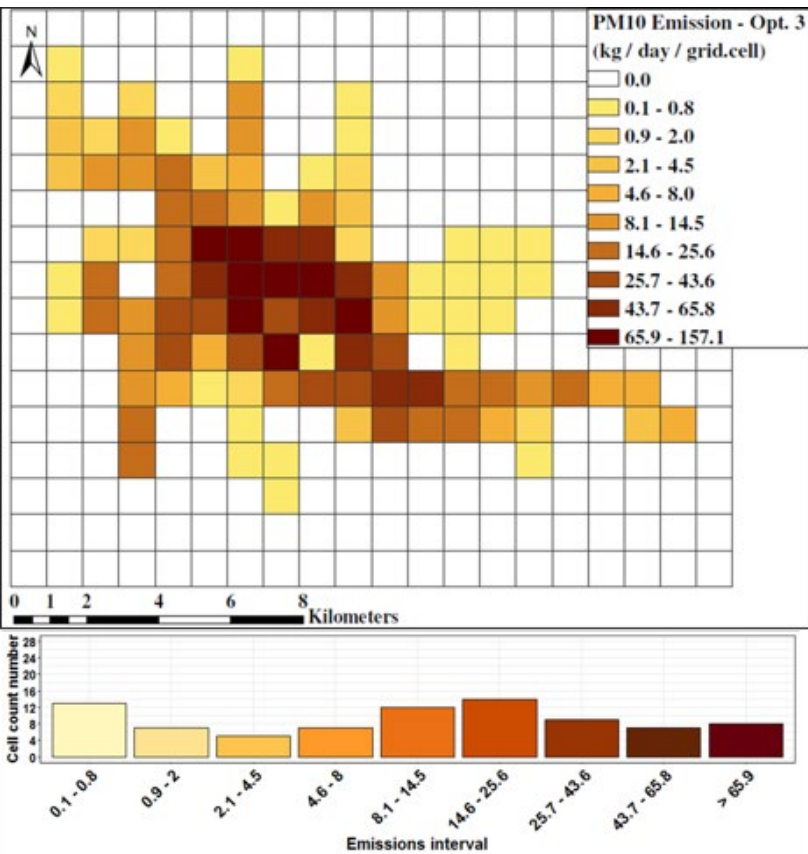

(b)

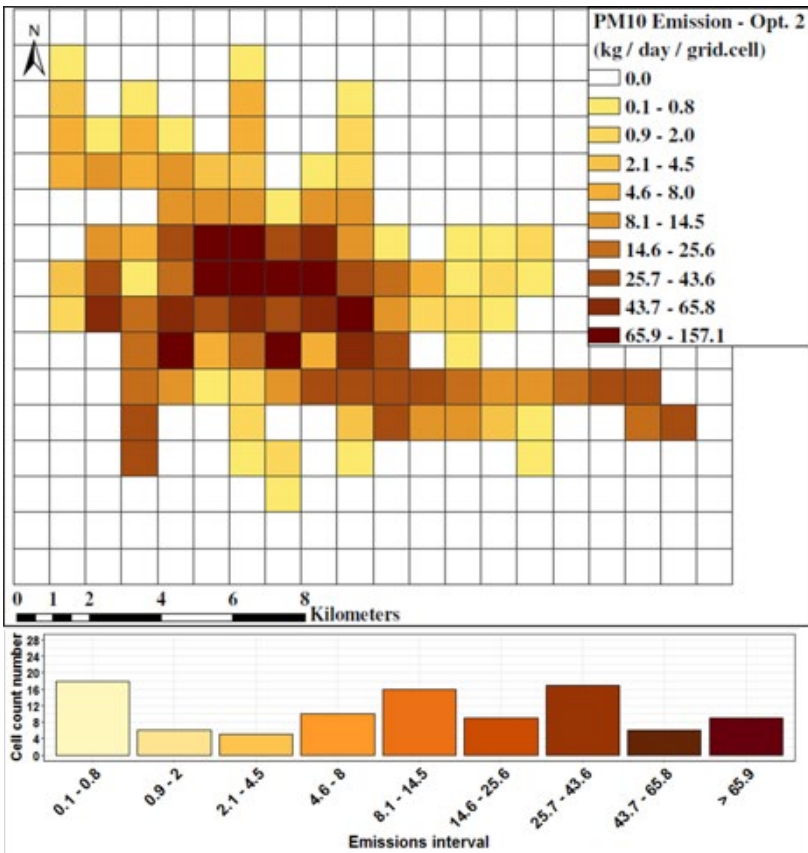

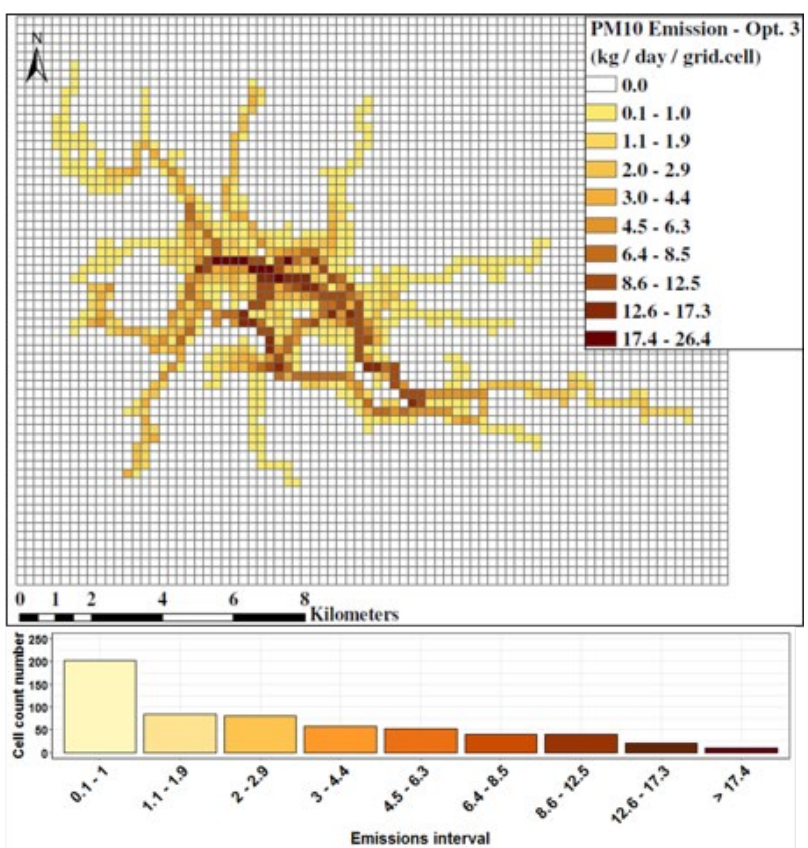

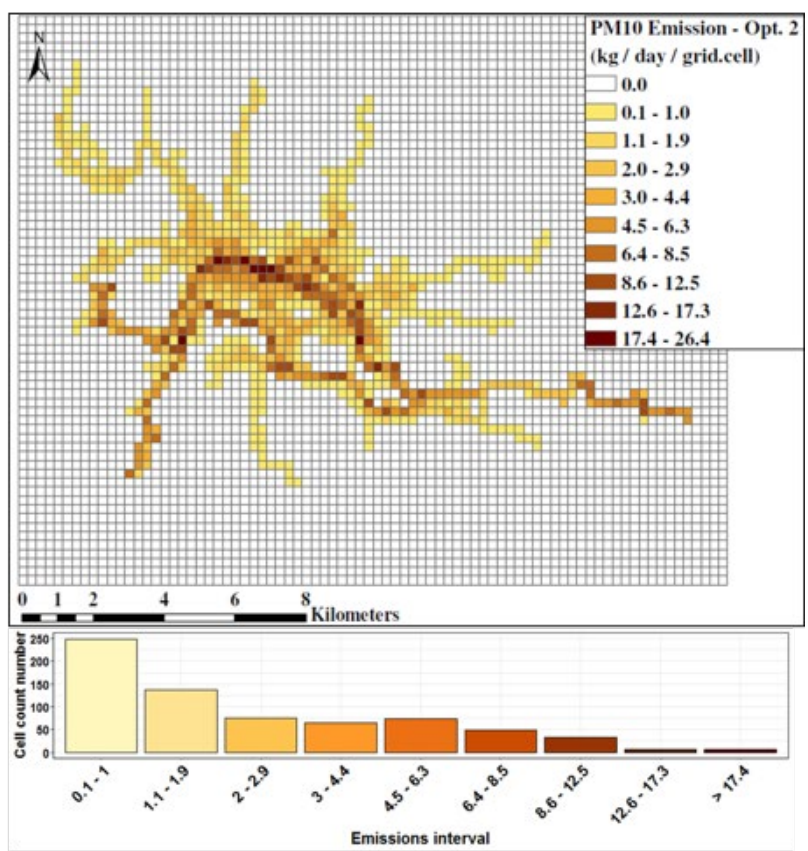

Fig. 3. Spatial distribution of $\mathrm{PM}_{10}$ emissions obtained with DROVE in Manizales, Colombia, for two different resolutions: $1 \mathrm{~km}$ (left) and $250 \mathrm{~m}$ (right); and three available disaggregation methodologies (a) Option 3, base case (road segment length + traffic flows). (b) Option 2 (road segment length + road type). (c) Option 1 (road segment length). The histogram with the grid-cell counts obtained for each emissions interval is shown below each map. 
(c)

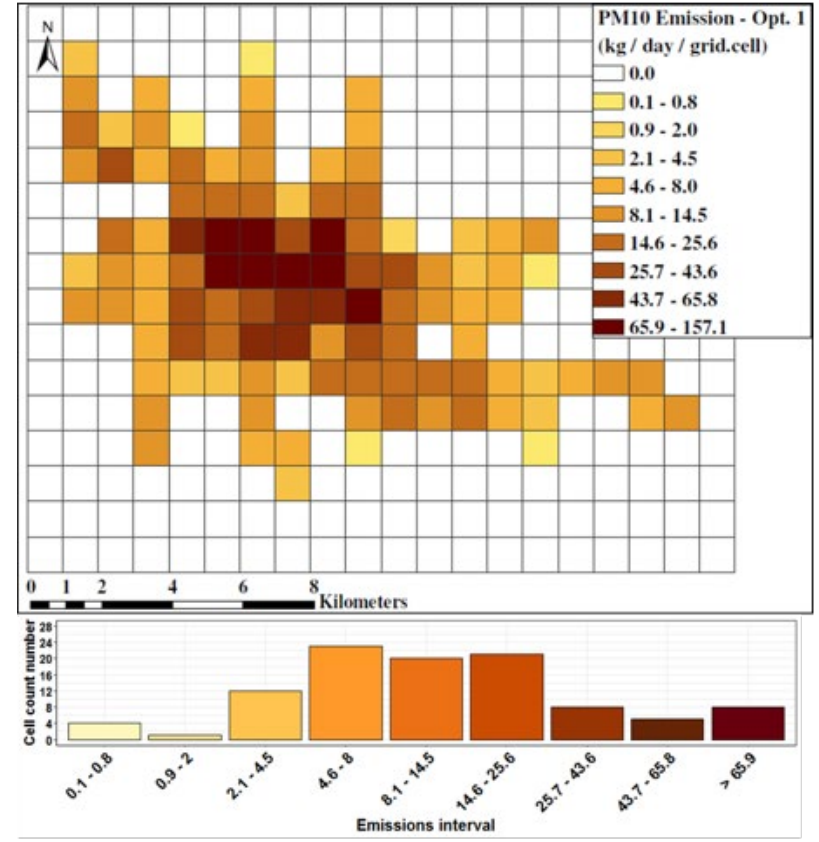

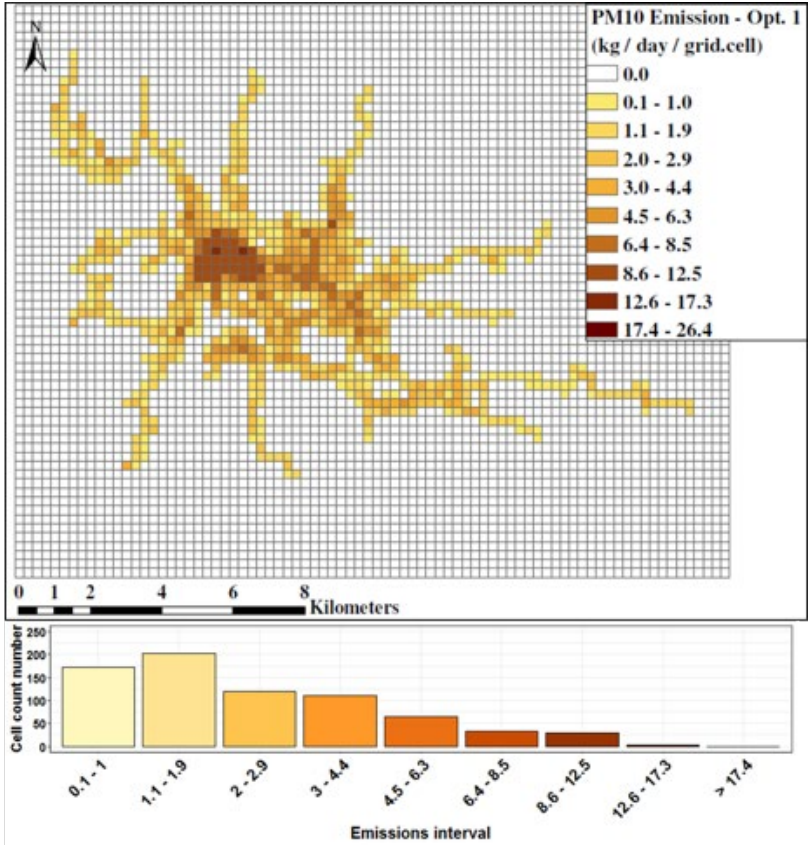

Fig. 3. (continued).

arterial and residential roads mainly (see Fig. 2). This type of spatial distribution does not reflect the effect of traffic flow in the three main avenues, which cross the city from east to west. On the other hand, spatial disaggregation obtained with the option 2 distribution (Fig. 3(b)), that includes a weight factor (calculated from aggregated traffic flow information of each vehicular category) to represent the difference in traffic among type of roads; shows higher emission fluxes in zones dominated by highway roads of the city. The emission maps obtained with this approximation were closer to results from the base case (option 3), in comparison with those obtained with option 1. A similar behavior was also reported by Saide et al. (2009) in Santiago, Chile, where the use of the complete road network distribution only was attributed to an underestimation of emission peaks and a more disperse representation of distributed vehicular emissions. This behavior was clearly improved when traffic counts data were included in the disaggregation approach.

Differences between emission maps from options 1 and 2 where quantified estimating the relative percent difference of total $\mathrm{PM}_{10}$ emission obtained per grid cell, against the reference emission distribution obtained from the base case. We present in Fig. 4(a) maps with the relative differences (\%) in emissions per grid cell for a resolution of $250 \mathrm{~m}$. Results obtained suggest that disaggregation with only road segments length (option 1) generates a major number of cells with differences higher than $100 \%$, located mainly in the boundaries of urban zone and the downtown area. Gómez et al. (2018) reported similar results in a previous emission disaggregation exercise in Manizales. This study obtained higher differences in the peripheral areas of the city when evaluating simplified top-down spatial disaggregation methods, concluding that traffic activity is not well reflected by the road density distribution over these surrounding areas. In terms of option 1 distribution, $50 \%$ of grid cells show differences higher than
$100 \%$ against the base case, while in option 2 distribution, $36 \%$ of grid cells show these differences (Fig. 4(b)). As well as, emission differences lower than $20 \%$ were obtained in the $17 \%$ of grid cells for the option 2 distribution and only in the $4 \%$ of grid cells of option 1, suggesting a better representation of type 2 spatial disaggregation.

It is important to highlight that different studies worldwide (e.g., Sun et al., 2016; Romero et al., 2020) reported the use of only road segment length density as the method for vehicular emissions disaggregation. Hence, this type of approach included in DROVE is a common and reliable methodology for vehicular emissions distribution. However, a more realistic emission distribution could be obtained when information about type of road and some traffic data (e.g., vehicular counts) are available, allowing the estimation of weight factors (fm) for the application of option 2 disaggregation in DROVE. Based on the results obtained when comparing the three disaggregation options, a simplification of the road network focused on dismiss some road segments with low traffic (tertiary roads mainly in residential areas), could be a good option for obtaining more accurate results in the spatial emissions distribution when only the road network distribution is available, as was proposed by Ossés de Eicker et al. (2008) in a previous vehicular disaggregation exercise in seven medium-sized Chilean cities.

\section{Temporal Distribution of $P M_{10}$ Emissions in Manizales}

Both hourly $\mathrm{PM}_{10}$ emission curves obtained with DROVE in Manizales (from local traffic counts and the automatic distribution) reflect the three traffic rush hours (07:00-08:00; 12:00-14:00; 18:00-19:00) of the city, and its effect on emission increments (Fig. 5). The highest daily $\mathrm{PM}_{10}$ emission peak (from the local distribution curve) was obtained at the end of the working day (18:00-19:00 hours) with hourly $\mathrm{PM}_{10}$ emissions in a range of $145-140 \mathrm{~kg} \mathrm{hr}^{-1}$. 
(a)

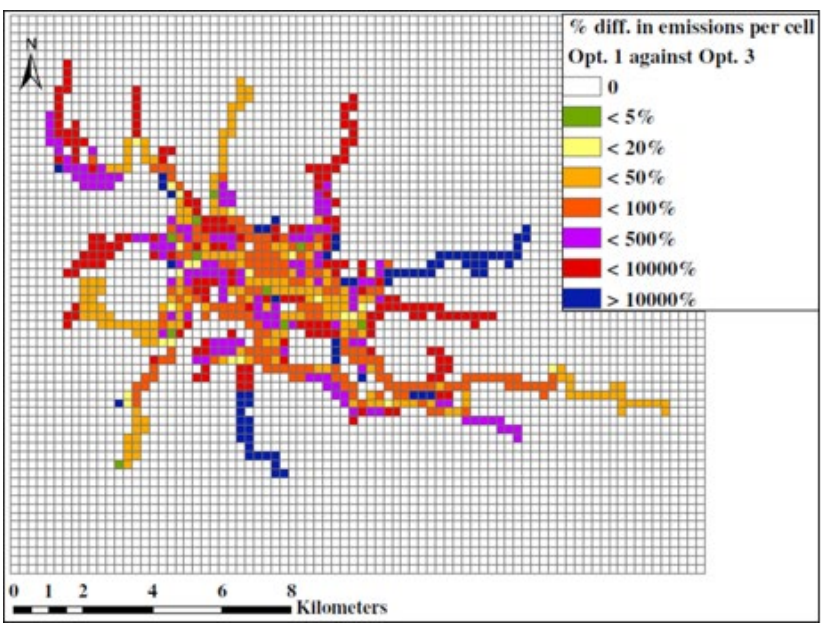

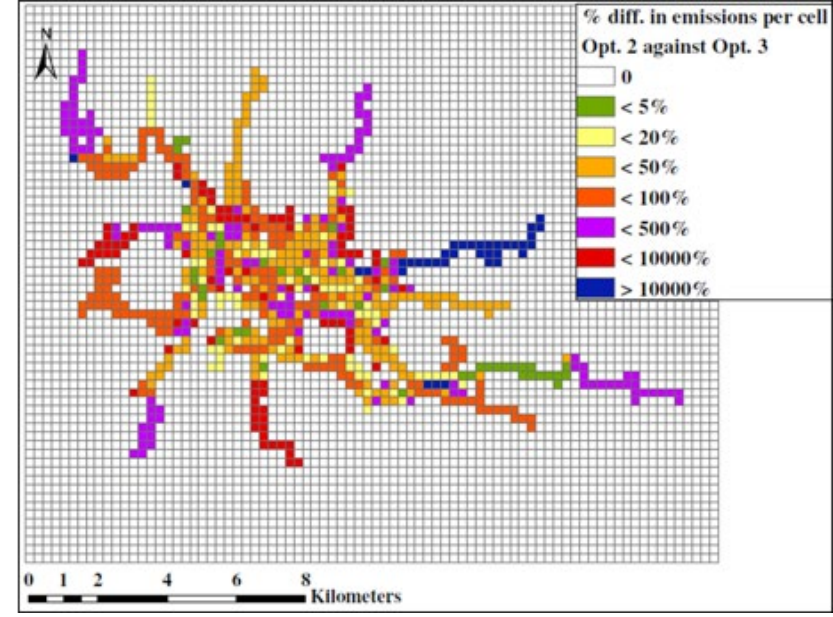

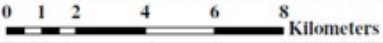

(b)

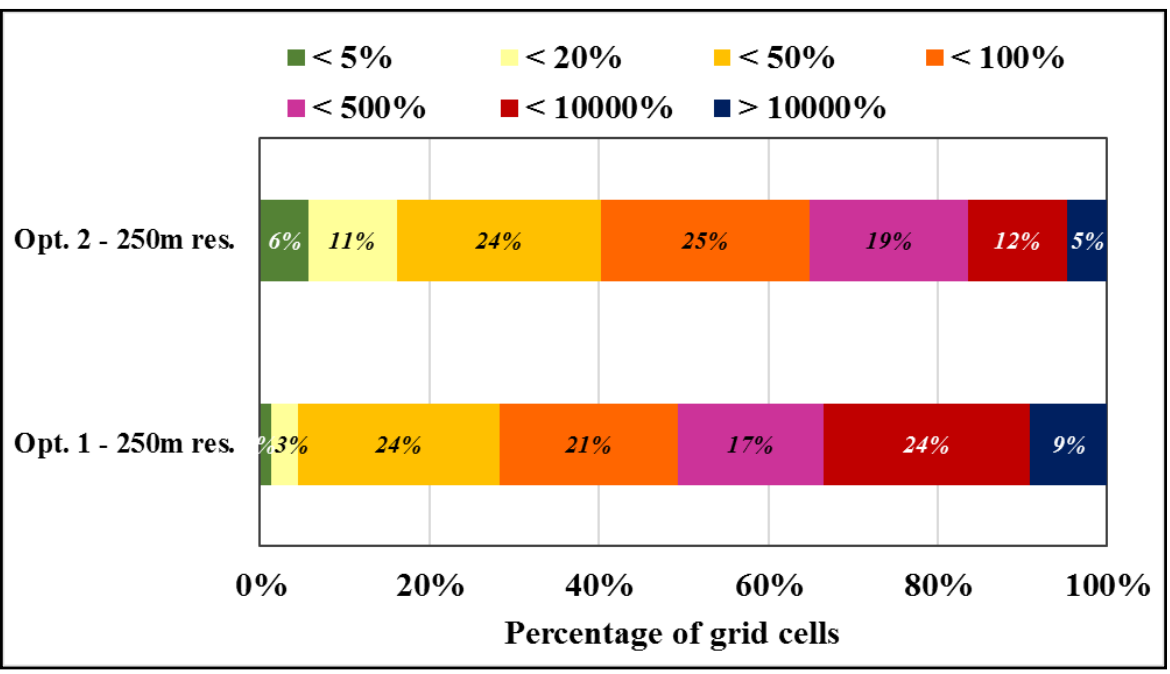

Fig. 4. Relative difference in $\mathrm{PM}_{10}$ emissions between reference spatial disaggregation (option 3) and the other available disaggregation methodologies. (a) Map with relative difference (\%) per grid cell. (b) Percentage of grid cells obtained from the reference intervals in the maps.

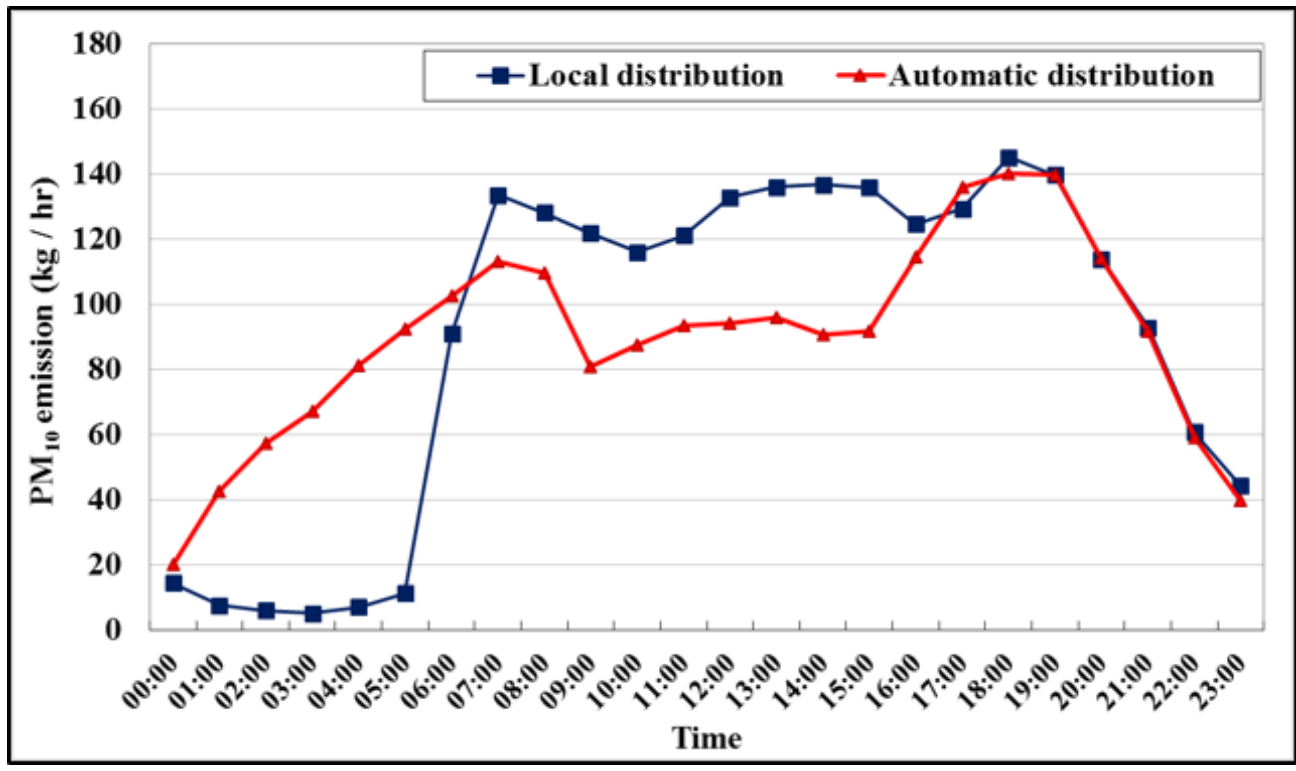

Fig. 5. Comparison of two temporal emission distribution curves obtained with DROVE for total hourly $\mathrm{PM}_{10}$ emission in Manizales. Results were obtained from a grid with $1 \mathrm{~km} \times 1 \mathrm{~km}$ spatial resolution. 
Comparing these results with those obtained from the use of an automatic temporal distribution in DROVE (Fig. 5), there is a good agreement in the emission curve obtained for the period of 17:00 to 00:00 hours. On the other hand, higher differences are observed during early morning hours (01:00-04:00) and mid-day (11:00-4:00 hours). Temporal emissions behavior obtained for the automatic distribution could be more realistic in bigger cities, where traffic during mid-day is low (due to longer distances from working areas to homes) and the main rush hours are presented at the beginning and end of working days. Recent studies in Chengdu, China (Zhou et al., 2019), and Sao Paulo, Brazil (Ibarra, 2017) have reported daily traffic flow behavior similar to that obtained with the automatic distribution. Results of these studies suggest the presence of two maximum traffic peaks at the beginning and end of working days, and a decrease of traffic profile at midday. However, this behavior is not a general rule for all big cities in the world. For example, Quaassdorff et al. (2016) reported in Madrid, Spain, a morning traffic profile almost constant until midday, with a maximum at the end of the working day. In that sense, the use of the temporal automatic distribution could be a proper option for obtaining an approximated hourly-disaggregated vehicular emission profile in regions with no information available of traffic behavior; but the use of a local temporal profile would be the most representative and recommended option.

Furthermore, the temporal and spatial emission distribution obtained with DROVE could provide proper emission data to feed air quality models. Tables with hourly vehicular emissions are associated with the identification (FID) of each grid cell in the domain (see examples in supplementary material, section $\mathrm{B}$, of tables with results obtained with DROVE in Manizales). Hence, through a GIS software it is possible to obtain the specific geographic coordinates of each grid cell (for example the centroid points) and correlate those with the distributed emissions. This information could be then used to feed emission preprocessor tools, which are commonly needed in air quality model simulations.

\section{Application of DROVE in Other Cities for the Spatial Disaggregation of Total PM10 Emissions}

Through the application of DROVE for spatially distributing total $\mathrm{PM}_{10}$ vehicular emissions in two distinct Latin American cities, we clearly demonstrate the flexibility of the code to be implemented in other regions worldwide. The first example of results is presented for the medium-sized city of Antofagasta, Chile (Fig. 6), where Chilean Environmental Ministry (https://mma.gob.cl/aire/) reported a total $\mathrm{PM}_{10}$ vehicular emission of 168.6 ton $\mathrm{yr}^{-1}$ for the EI-2018. Results obtained when using the road length segments approximation (option 1 in Fig. 6(a)) suggest higher emission hotspots around the east and northeast areas of the city. On the other hand, clear differences were obtained (Fig. 6(b)) when using option 2 distribution approximation (assuming the same weight factors (fm) used in Manizales). As it is shown in Fig. 6, differences in emissions distribution between these two approaches are higher when spatial resolution increases. For example, the analysis of emission hotspots for option 2 approach suggest that grid cells with maximum emission values (higher than 0.52 ton $\mathrm{yr}^{-1}$ ), covered $9 \%$ of total grid cells and are located in highway roads mainly. While in option 1 results there were no grid cells with emission values higher than 0.52 ton $\mathrm{yr}^{-1}$.

The same exercise was performed in the megacity of Bogotá, Colombia. The District Environment Secretary reported a total emission of 1318 ton $\mathrm{yr}^{-1}$ of $\mathrm{PM}_{10}$ from onroad vehicular sources for the EI-2014 (SDA, 2017). Emission maps obtained with option 1 approach (Fig. 7(a)) suggest a uniform $\mathrm{PM}_{10}$ distribution with some critical regions such as the west zone, where it is possible to differentiate a few emission hotspots. In the case of option 2 distribution (Fig. 7(b)), emission hotspots are strong and highlighted with the increase in spatial resolution. In the emission map of $250 \mathrm{~m}$ resolution (Fig. 7(b) right) it is possible to note that emission hotspots were related with principal roads of the city such as Boyacá avenue, 68 highway, North freeway, among others. Similar result was obtained in Bogotá in comparison with Antofagasta, analyzing emission hotspots for option 2 approach, which shows that grid cells with maximum emission values (higher than 0.6 ton $\mathrm{yr}^{-1}$ ) covered $8 \%$ of total grid cells. While in option 1 results there were no grid cells with emission values higher than 0.6 ton $\mathrm{yr}^{-1}$. Comparing the two spatial approaches applied in DROVE for $\mathrm{PM}_{10}$ emission distribution in Bogotá, with the bottomup emission distribution maps reported by Mangones et al. (2019), the results obtained from option 2 show qualitatively a better agreement. Tables with examples of disaggregation results for all pollutants described in Table 1 for Antofagasta and Bogotá are included in supplementary material, section B.

Finally, we present in Table 2 a comparison of computational times for the emissions disaggregation exercises performed with DROVE for the three cities analyzed in this paper. The $\mathrm{R}$ code simulations were performed in a 64 bits laptop with 6 GB RAM and a Core i7-3517U processor. In terms of only spatial disaggregation, simulated elapsed times obtained for the medium-sized cities where lower than 2.5 minutes, that was the computational time obtained in Manizales for the highest resolution $(250 \mathrm{~m})$ and the option 3 disaggregation exercise. In the case of Bogotá, a region with almost ten times higher number of road length segments, the elapsed time simulation was around 6.7 minutes for the option 2 in a grid of $250 \mathrm{~m}$ resolution. On the other hand, when temporal distribution was activated, simulation periods increased in a proportion from 10 to 20 times higher with respect to only-spatial distribution.

Based on results presented in Table 2, the only possible limitation of DROVE to be used in other regions of the world is related with computational resources, mainly when both spatial and temporal disaggregation are performed at a high spatial resolution for big areas, for example, at a country or regional scale. In those cases, user probably needs a machine with relatively strong processing capacity to support computational times in the order of hours or days. As we discussed before, the only limitation in terms of input information is to have the data of total vehicular emissions for the region of study (either at a regional, country or city scale). As DROVE allows the user to include emissions per vehicle category, if emission inputs for other types of 
(a)

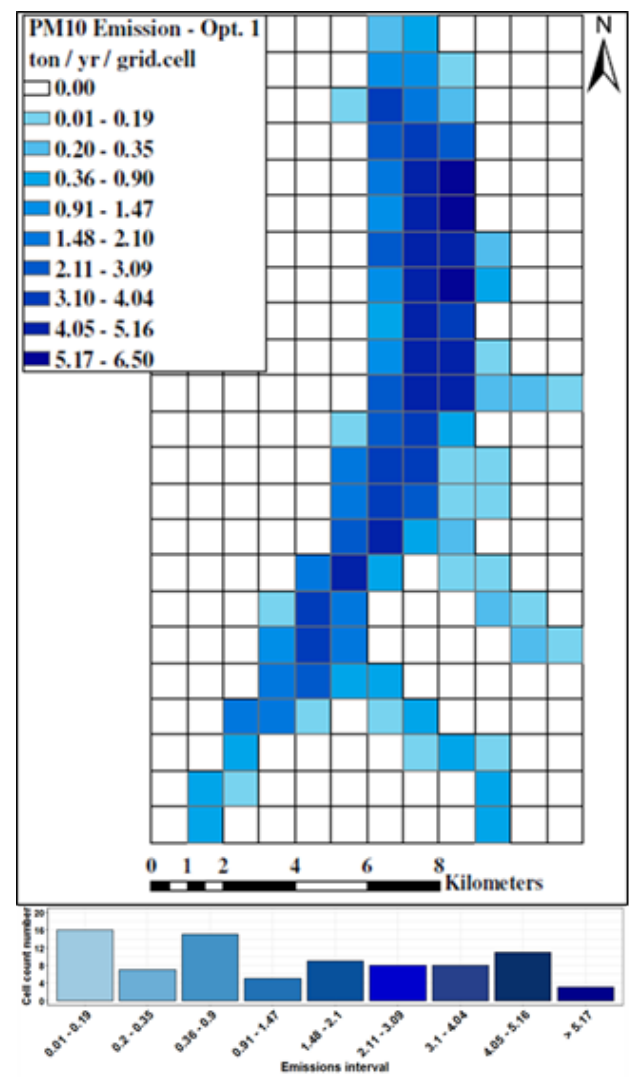

(b)

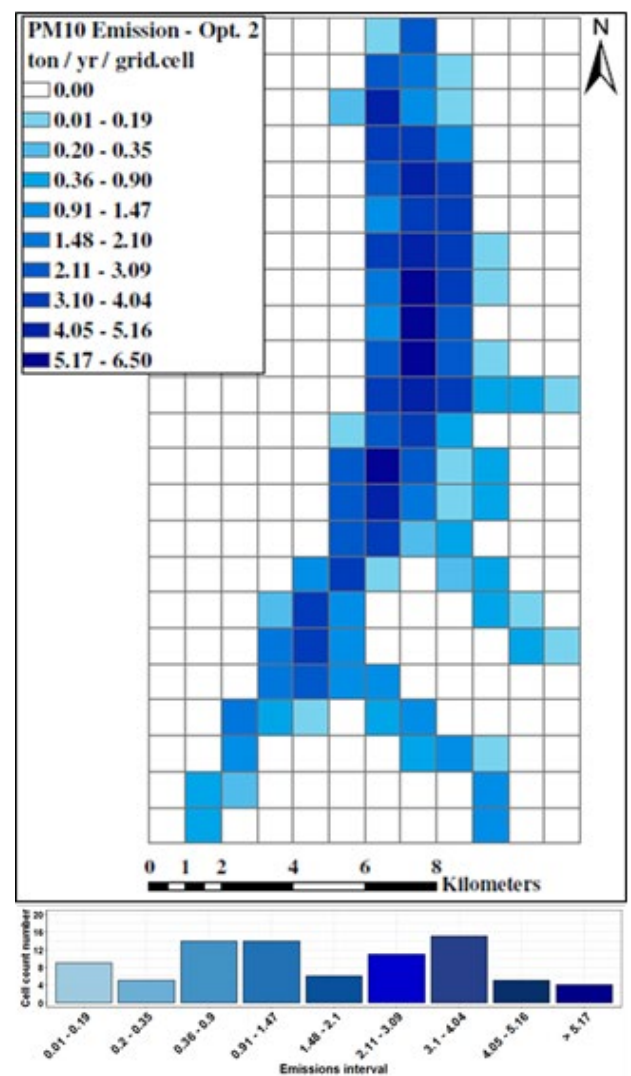

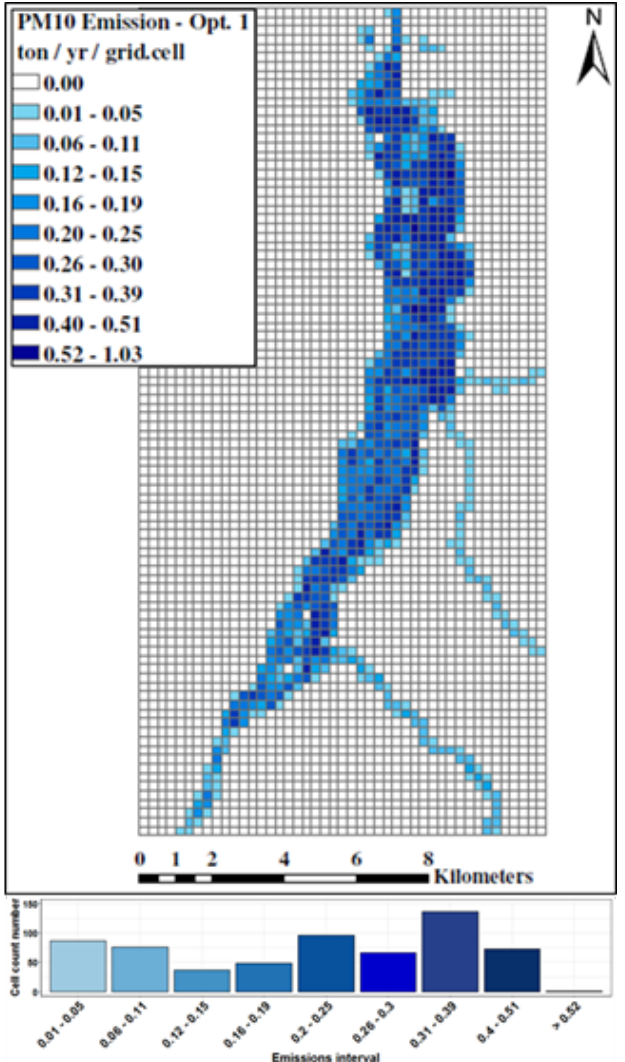

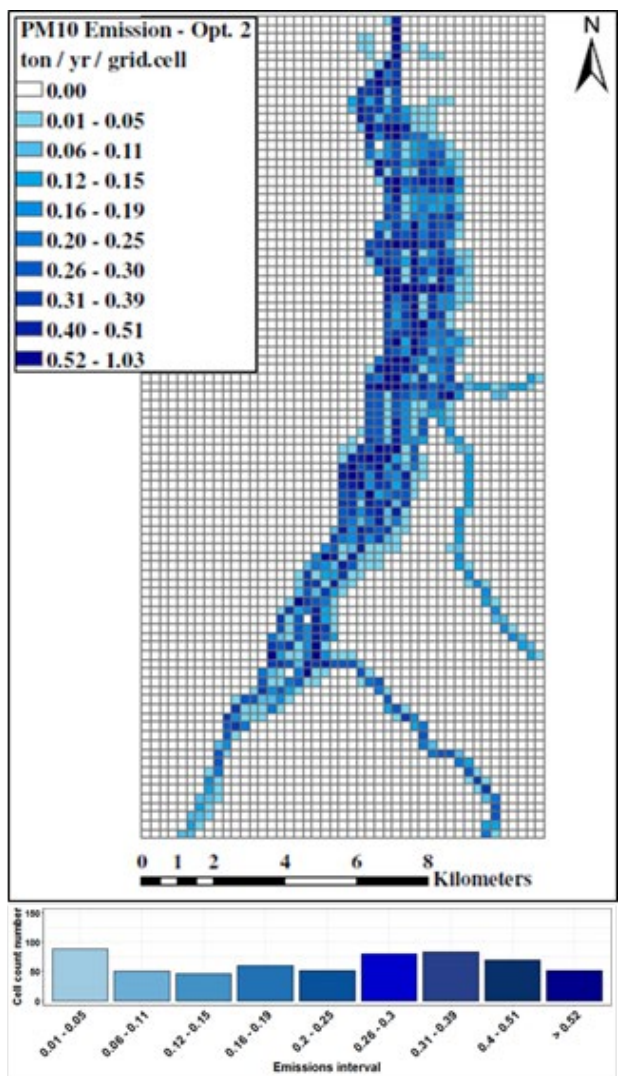

Fig. 6. Spatial distribution of $\mathrm{PM}_{10}$ emissions obtained with DROVE in Antofagasta, Chile for two different resolutions: $1 \mathrm{~km}$ (left) and $250 \mathrm{~m}$ (right); and two disaggregation methodologies a) Option 1 (road segment length). b) Option 2 (road segment length + road type). The histogram with the grid-cell counts obtained for each emissions interval is shown below each map. 
(a)

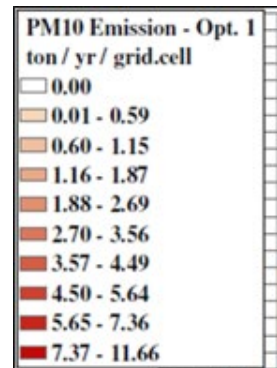
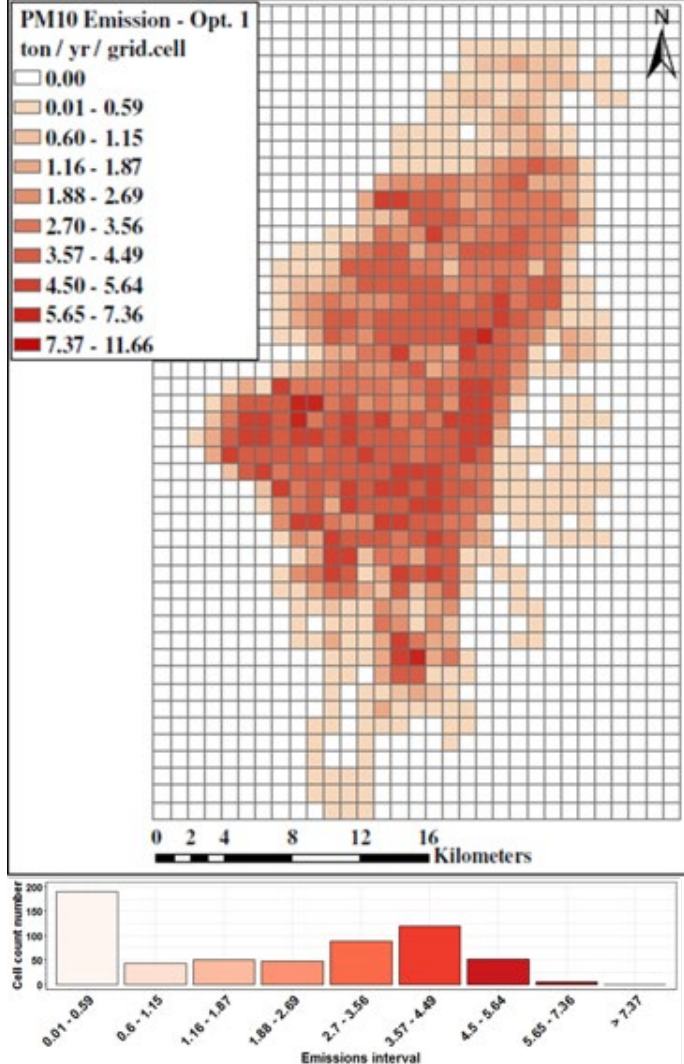

(b)

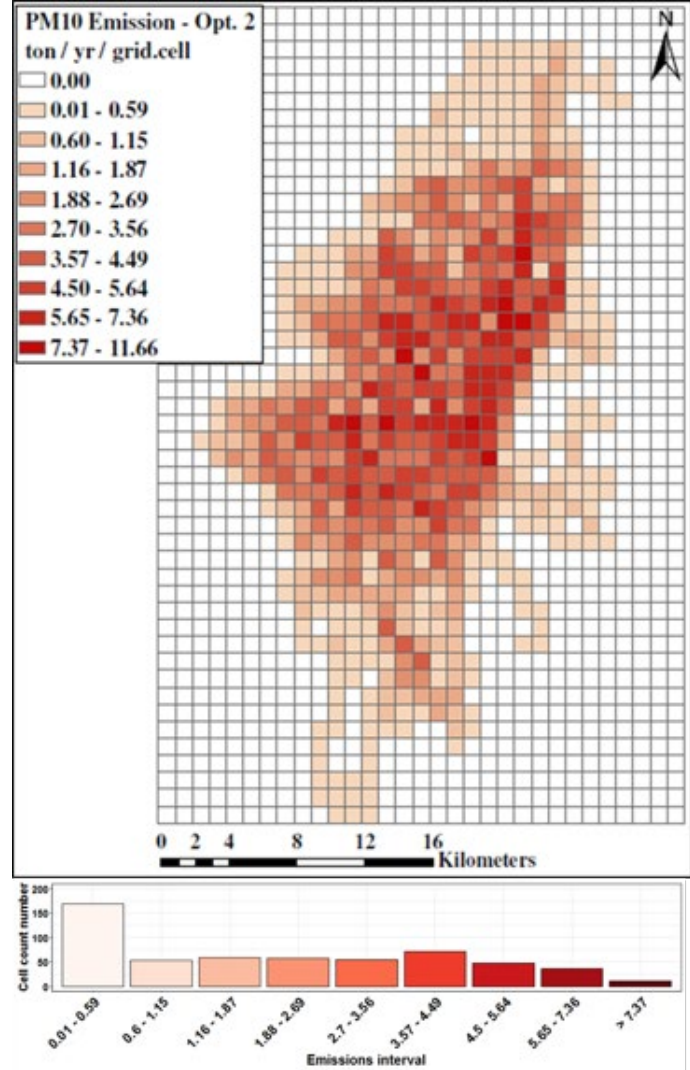

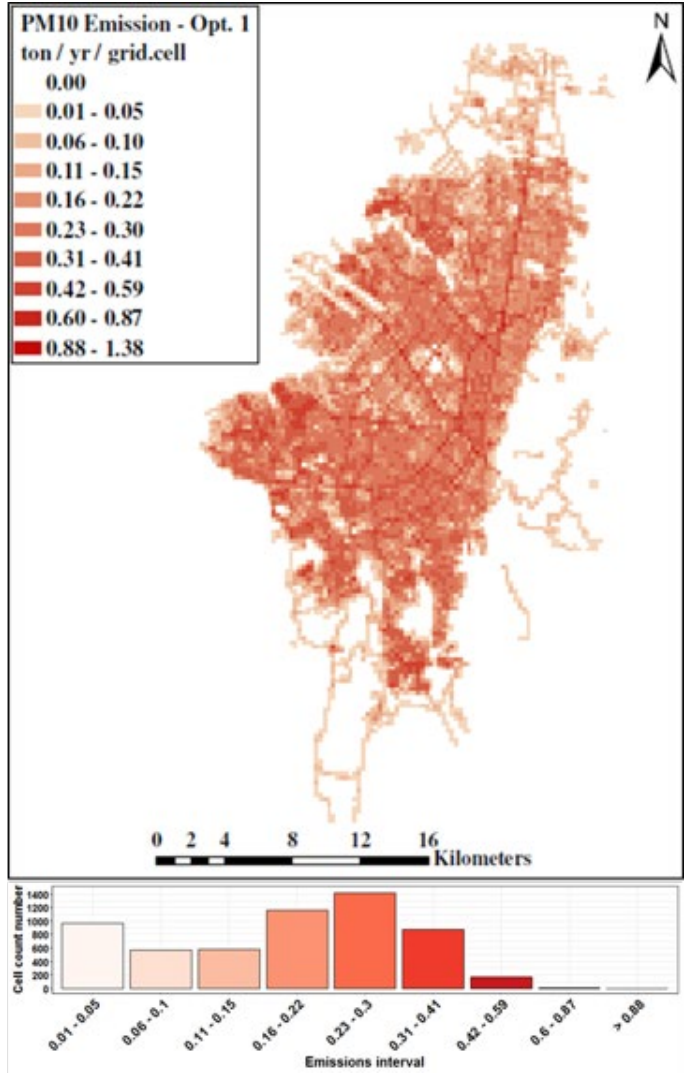

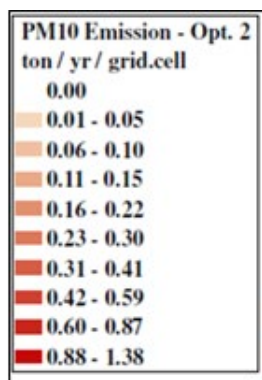

$\bigwedge^{N}$

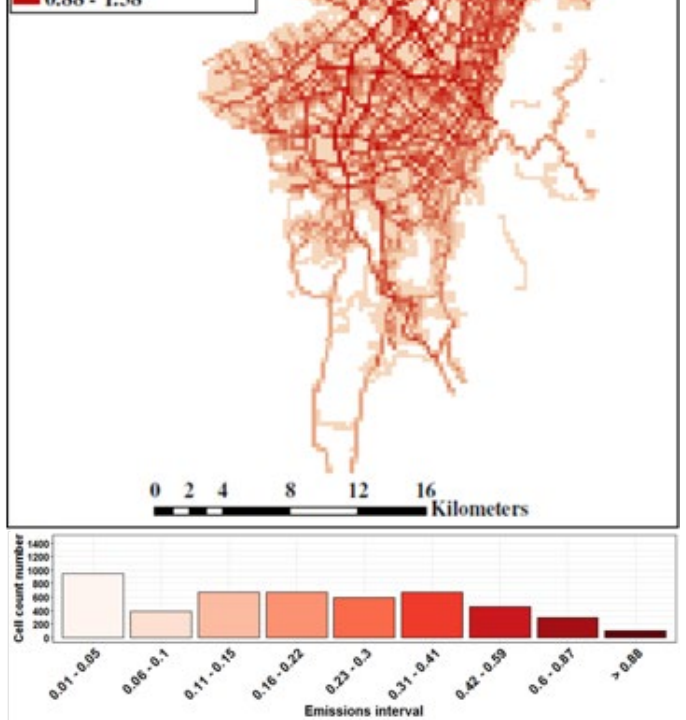

Fig. 7. Spatial distribution of $\mathrm{PM}_{10}$ emissions obtained with DROVE in Bogotá, Colombia for two different resolutions: $1 \mathrm{~km}$ (left) and $250 \mathrm{~m}$ (right); and two disaggregation methodologies a) Option 1 (road segment length). b) Option 2 (road segment length + road type). The histogram with the grid-cell counts obtained for each emissions interval is shown below each map. 


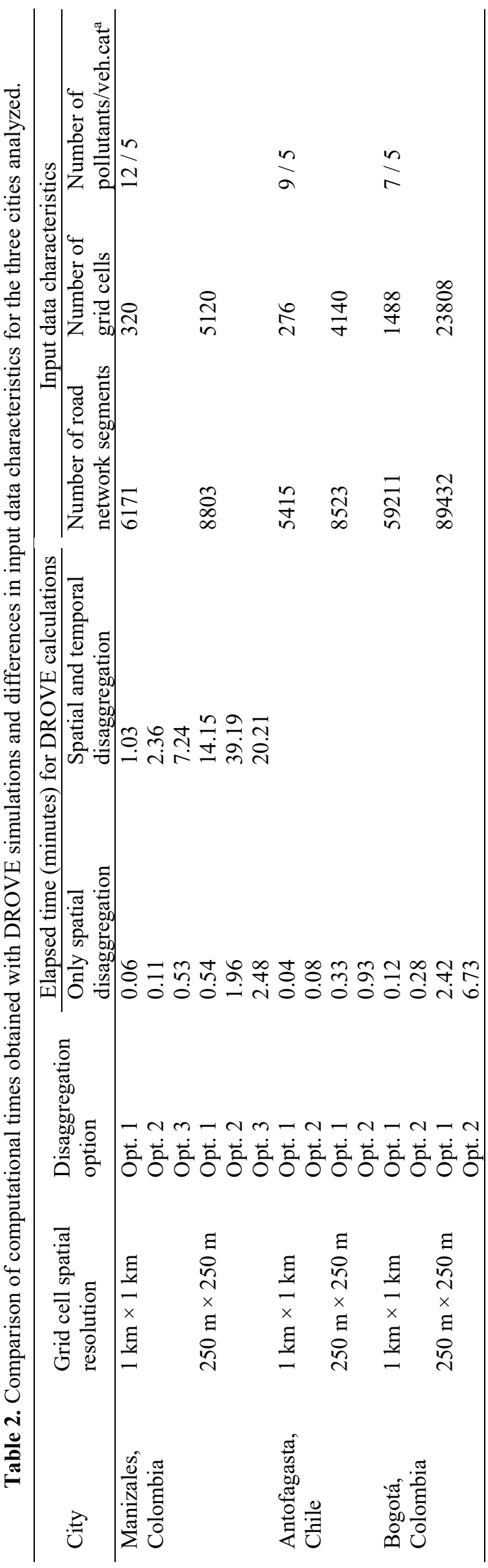

vehicles than those presented in this study are available, user could include these new categories editing the proper section in the DROVE UserInterface.R file. Finally, it is important to remark that when option 2 is chosen to perform the disaggregation, there are three types of roads available in DROVE: highway (primary), arterial (secondary) and residential (tertiary) roads. In that sense, user should associate the types of roads included in the road network distribution to the three types of roads available. An example of this association when road network is obtained from OpenStreetMaps is shown in Table S1 of supplementary material.

\section{CONCLUSIONS}

We introduce a new open-source code named as DROVE for the space and time disaggregation of on-road vehicle emissions, with the flexibility to be implemented in any region of the world. The algorithm allows to estimate disaggregation factors for each grid cell in a domain defined by user. Disaggregation options include three possible approximations for spatial emissions disaggregation, and two possible temporal distributions for obtaining gridded hourly emissions.

A successfully exercise of on-road vehicular emissions disaggregation using DROVE was presented for the mediumsized cities of Manizales, Colombia, and Antofagasta, Chile; as well as for the megacity of Bogotá, Colombia; demonstrating the flexibility of DROVE to be implemented in different regions worldwide. In the case of Manizales, the spatial distribution of $\mathrm{PM}_{10}$ emissions suggested the presence of emission hotspots at the downtown area (geographic center) and south region - zone characterized by the presence of the municipal-bus terminal. Furthermore, comparison of the three different spatial disaggregation options, allowed us to conclude that option 1 distribution (that use only road segments length) do not reflect the effect of traffic flow in the three main avenues, obtaining $50 \%$ of grid cells with percentage $\mathrm{PM}_{10}$ emission differences higher than $100 \%$ against the reference case (option 3 - road segments length + traffic flows). In the case of option 2 disaggregation (that use road segments length + road type), this approach shows higher emission fluxes in zones dominated by highway roads of the city and a better agreement with respect to the base case, showing a lower quantity of grid cells $(36 \%)$ with differences higher than $100 \%$ in $\mathrm{PM}_{10}$ emissions. In this sense, option 2 permits to have a good approximation when traffic models are not available.

Results obtained suggest also the impact of increasing the spatial resolution in the analysis of more detailed emission hotspots, showing also the capability of DROVE for obtaining spatial disaggregated emissions at two high resolutions of 1 $\mathrm{km}$ and $250 \mathrm{~m}$.

DROVE could contribute with air quality management in urban areas where bottom-up information of vehicular activity is scarce, and there are difficulties in the determination of pollutant emission hotspots at a high-spatial resolution. Furthermore, this code provides a resolved temporal and spatial emission distribution that could be used in air quality modeling exercises. 


\section{ACKNOWLEDGMENTS}

The authors acknowledge the financial support given by Corporación Autónoma Regional de Caldas (CORPOCALDAS) and Universidad Nacional de Colombia Sede Manizales through Convenio Interadministrativo de Asociación 107-2018. Furthermore, authors acknowledge financial support given by Departamento Administrativo de Ciencia, Tecnología e Innovación (COLCIENCIAS) through "Convocatoria Estancias Postdoctorales 811".

Authors acknowledge professor Sonia Mangones from Universidad Nacional de Colombia Sede Bogotá, for helping us to obtain traffic information from the traffic model EMME.

\section{DISCLAIMER}

The authors declare no conflict of interest and no competing financial relationships that could influence data and results reported in this paper.

Web page of DROVE: https://sites.google.com/unal.ed u.co/drove/home

\section{SUPPLEMENTARY MATERIAL}

Supplementary data associated with this article can be found in the online version at https://doi.org/10.4209/aaqr.2 020.04.0184

\section{REFERENCES}

Alam, M.S., Duffy, P., Hyde, B. and McNabola, A. (2018). Downscaling national road transport emission to street level: A case study in Dublin, Ireland. J. Cleaner Prod. 183: 797-809. https://doi.org/10.1016/j.jclepro.2018.02.206

Borge, R., Lumbreras, J., Pérez, J., de la Paz, D., Vedrenne, M., de Andrés, J.M. and Rodríguez, M.E. (2014). Emission inventories and modeling requirements for the development of air quality plans. Application to Madrid (Spain). Sci. Total Environ. 466-467: 809-819. https://doi.org/10.101 6/j.scitotenv.2013.07.093

Corporación Autónoma Regional de Caldas (CORPOCALDAS) and Universidad Nacional de Colombia Sede Manizales (UNAL) (2019). Aplicación de herramientas de simulación atmosférica en el estudio de la calidad del aire en Manizales. Convenio Interadministrativo 107-2018. In Spanish. Manizales, Colombia.

de Sousa, A., Hoinaski, L., Barros, T. and Castelan, R. (2019). A methodology for high resolution vehicular emissions inventories in metropolitan areas: Evaluating the effect of automotive technologies improvement. Transp. Res. Part D 77: 303-319. https://doi.org/10.1016/ j.trd.2019.10.007

Departamento Nacional de Estadística (DANE) (2020). Censo Nacional de Población y Vivienda 2018. Colombia (in Spanish). https://sitios.dane.gov.co/cnpv/\#!/cua_som

Gómez, C.D., González, C.M., Osses, M. and Aristizábal, B.H. (2018). Spatial and temporal disaggregation of the on-road vehicle emission inventory in a medium-sized Andean city. Comparison of GIS-based top-down methodologies. Atmos. Environ. 179: 142-155. https://doi.org/10.1016/j.atmosenv.2018.01.049

González, C.M., Ynoue, R.Y., Vara-Vela, A., Rojas, N.Y. and Aristizábal, B.H. (2018). High-resolution air quality modeling in a medium-sized city in the tropical Andes: Assessment of local and global emissions in understanding ozone and $\mathrm{PM}_{10}$ dynamics. Atmos. Pollut. Res. 9: 934948. https://doi.org/10.1016/j.apr.2018.03.003

Ibarra-Espinosa, S. (2017). Air pollution modeling in São Paulo using bottom-up vehicular emissions inventories. Ph.D Thesis. Universidade de São Paulo, Sao Paulo, Brazil. https://www.iag.usp.br/pos/sites/default/files/t_se rgio_a_i_espinosa_corrigida.pdf

Ibarra-Espinosa, S., Ynoue, R.Y., Ropkins, K., Zhang, X. and Dias, E. (2020). High spatial and temporal resolution vehicular emissions in south-east Brazil with traffic data from real-time GPS and travel demand models. Atmos. Environ. 222: 117136. https://doi.org/10.1016/j.atmosenv. 2019.117136

Instituto Nacional de Estadística de Chile (INE) (2002). Censo 2017. http://resultados.censo2017.cl/Region?R=R02

Loibl, W., Orthofer, R. and Winiwarter, W. (1993). Spatially disaggregated emission inventory for anthropogenic NMVOC in Austria. Atmos. Environ. 27: 2575-2590. https://doi.org/10.1016/0960-1686(93)90031-S

Mangones, S.C., Jaramillo, P., Fischbeck, P. and Rojas, N.Y. (2019). Development of a high-resolution traffic emission model: Lessons and key insights from the case of Bogotá, Colombia. Environ. Pollut. 253: 552-559. https://doi.org/10.1016/j.envpol.2019.07.008

Manizales Cómo Vamos (2019). Informe de calidad de vida Manizales 2019. (in Spanish). http://manizalescomovamo s.org/informe2019/

Ministerio del Medio Ambiente de Chile (MMA). Información de emisiones atmosféricas Chile. (in Spanish). https://datosretc.mma.gob.cl/group/emisiones-al-aire

Ossés de Eicker, M., Zah, R., Triviño, R. and Hurni, H. (2008). Spatial accuracy of a simplified disaggregation method for traffic emissions applied in seven mid-sized Chilean cities. Atmos. Environ. 42: 1491-1502. https://doi.org/10.1016/j.atmosenv.2007.10.079

Parra, R., Jiménez, P. and Baldasano, J.M. (2006). Development of the high spatial resolution EMICAT2000 emission model for air pollutants from the north-eastern Iberian Peninsula (Catalonia, Spain). Environ. Pollut. 140: 200-219. https://doi.org/10.1016/j.envpol.2005.07.021

Quaassdorff, C., Borge, R., Pérez, J., Lumbreras, J., de la Paz, D. and de Andrés, J.M. (2016). Microscale traffic simulation and emission estimation in a heavily trafficked roundabout in Madrid (Spain). Sci. Total Environ. 566567: 416-427. https://doi.org/10.1016/j.scitotenv.2016.0 5.051

Romero, Y., Chicchon, N., Duarte, F., Noel, J., Ratti, C. and Nyhan, M. (2020). Quantifying and spatial disaggregation of air pollution emissions from ground transportation in a developing country context: Case study for the Lima Metropolitan Area in Peru. Sci. Total Environ. 698: 
134313. https://doi.org/10.1016/j.scitotenv.2019.134313

Sahu, S.K., Beig, G. and Parkhi, N. (2014). Critical Emissions from the Largest On-Road Transport Network in South Asia. Aerosol Air Qual. Res. 14: 135-144. https://doi.org/10.4209/aaqr.2013.04.0137

Saide, P., Zah, R., Osses, M. and Ossés de Eicker, M. (2009). Spatial disaggregation of traffic emission inventories in large cities using simplified top-down methods. Atmos. Environ. 43: 4914-4923. https://doi.org/10.1016/j.atmos env.2009.07.013

Secretaría Distrital de Ambiente (SDA) (2017). Documento técnico de soporte. Modificación del decreto 98 de 2011. (in Spanish). Bogotá, Colombia. http://www.ambientebo gota.gov.co/c/document_library/get_file?uuid $=\mathrm{d} 134928 \mathrm{c}$ -8756-4a69-ad18-ff09bb822fef\&groupId=3564131

Steer Davies Gleave (2017). Plan Maestro de Movilidad de Manizales. Línea base y diagnóstico de la situación actual de movilidad de Manizales. In Spanish. Manizales, Colombia.

Sun, S., Jiang, W. and Gao, W. (2016). Vehicle emission trends and spatial distribution in Shandong province, China, from 2000 to 2014. Atmos. Environ. 147: 190-199. https://doi.org/10.1016/j.atmosenv.2016.09.065

Thunis, P., Clappier, A., Tarrason, L., Cuvelier, C., Monteiro,
A., Pisoni, E., Wesseling, J., Belis, C.A., Pirovano, G., Janssen, S., Guerreiro, C. and Peduzzi, E. (2019). Source apportionment to support air quality planning: Strengths and weaknesses of existing approaches. Environ. Int. 130: 104825. https://doi.org/10.1016/j.envint.2019.05.019

Tuia, D., Ossés de Eicker, M., Zah, R., Osses, M., Zarate, E. and Clappier, A. (2007). Evaluation of a simplified topdown model for the spatial assessment of hot traffic emissions in mid-sized cities. Atmos. Environ. 41: 36583671. https://doi.org/10.1016/j.atmosenv.2006.12.045

United Nations, Department of Economic and Social Affairs, Population Division (2019). World Urbanization Prospects: The 2018 Revision (ST/ESA/SER.A/420). United Nations, New York.

Zhou, Z., Tan, Q., Liu, H., Deng, Y., Wu, K., Lu, C. and Zhou, X. (2019). Emission characteristics and highresolution spatial and temporal distribution of pollutants from motor vehicles in Chengdu, China. Atmos. Pollut. Res. 10: 749-758. https://doi.org/10.1016/j.apr.2018.12.002

Received for review, April 30, 2020 Revised, July 22, 2020 Accepted, August 10, 2020 